\title{
Psychological Science's Replicability Crisis and What It Means for Science in the Courtroom
}

\author{
Jason M. Chin \\ University of Toronto
}

\begin{abstract}
In response to what has been termed the "replicability crisis," great changes are currently under way in how science is conducted and disseminated. A question therefore arises over how such change impacts law's treatment of scientific evidence. The present standard for the admissibility of scientific evidence in federal courts in the U.S. asks judges to play the role of gatekeeper, determining if the proffered evidence conforms with several indicia of scientific validity. The replicability crisis, however, has demonstrated that these indicia frequently fail to adequately capture, or have lagged behind, science's best practices. Therefore, this article suggests that as much as the replicability crisis highlights serious issues in the scientific process, it should have similar implications and actionable consequences for legal practitioners and academics. The Article concludes with some suggestions to help ensure that legal decisions are influenced by the best science has to offer.
\end{abstract}

Keywords: scientific evidence, research methods, admissibility, replicability, Daubert

Science-psychological science especially-is undergoing a process of massive change. Spurred by startling revelations about the dependability of its findings (i.e., the replicability crisis; see Pashler \& Wagenmakers, 2012 for a review), ${ }^{1}$ generally accepted practices are being reformed at a pace and ferocity with scant precedent. Throughout this process longstanding recommendations (Cohen, 1994) and norms (American Psychological Association, 2009; Wilkinson, 1999) have become binding as academic journals - the very outlet for scientific work- have changed their review process and requirements for publication (e.g., Nature, Science, Psychological Science). In tandem with these responses, well-funded organizations have sprouted up, providing further research and infrastructure to scaffold these changes (e.g., The Open Science Framework). While the swift reaction to the crisis is laudable, the fact that evidently substandard generally accepted practices persisted for so long poses important questions concerning how law should treat scientific evidence, and how it should react to the changes occurring in science.

In evaluating scientific evidence, courts rely on both testimony from qualified experts in a field (Federal Rules of Evidence, Rule 702, 2011a) and after Daubert v. Merrell Dow (1993), the judge's own evaluation of the validity of this evidence. In fact, Daubert

\section{This article was published Online First May 5, 2014.}

Jason M. Chin, Faculty of Law, University of Toronto.

The ideas contained herein were inspired by Helena Likwornik's visionary course and research, and for that I am endlessly grateful. For perspicacious feedback on previous versions of this paper I am deeply indebted to Tom Budziakowski, Matt Hodgson, Eric Leinveer, Scott Lilienfeld, Robin McNamara, Larysa Workewych, and several anonymous reviewers. Thanks also to Eric Ip for providing me the time and resources to prepare this article.

Correspondence concerning this article should be addressed to Jason M. Chin, University of Toronto Faculty of Law, 84 Queen's Park, Toronto, Ontario, Canada. E-mail: jason.chin@mail.utoronto.ca and its two companion cases (General Electric Co. v Joiner, 1997 , "Joiner"; Kumho Tire Co. v Carmichael, 1999, "Kumho"; i.e., the "The Daubert Trilogy") are the leading U.S. Supreme Court authority on the admissibility of scientific evidence and are binding on federal courts. ${ }^{2}$ Daubert's innovation is the requirement that judges play a gatekeeper role, not just determining whether a scientific finding or method has reached a sufficient consensus among scientists, but evaluating the validity of the science itself. Posing both important practical considerations, and questions fundamental to the philosophy of science, Daubert has attracted a great deal of academic interest (e.g., see Beecher-Monas, 1998: Chesebro, 1994; Faigman \& Monahan, 2009; Schwartz, 1997).

The replicability crisis, however, exposes a fundamental concern with Daubert. In particular, it suggests that generally accepted practices also affect the way in which research is conducted, thus complicating judicial analysis of scientific findings. As shall be described below, the most important prescription this essay has to offer is that the legal treatment of scientific evidence track new measures developed in science to improve its dependability. This is especially important because many of the concerns raised during the replicability crisis have been raised before over the past several decades, with little substantive change to show for it. Moreover, while the scientific stakes of allowing unreliable findings to permeate bodies of research are high, the stakes are just as high within law where, outside of limited appellate review, there is less opportunity for self-correction. Law must take measures to ensure that the science that reaches decision makers is a result of best practices, and not merely those that are generally accepted.

\footnotetext{
${ }^{1}$ The term crisis, while certainly strong, tracks language used in the field and is thus useful in succinctly conveying meaning in the present essay. But it must be noted that, perhaps due to science taking this "crisis" so seriously, a great deal of progress has been made and this crisis may be abating.

${ }^{2}$ But as shall be described later in the essay, several states have refrained from adopting the Daubert framework.
} 
To address the above goal, this essay follows a simple structure. After a brief review of the law and the replicability crisis, I analyze the Daubert factors in light of the causes and lessons of the replicability crisis. This analysis suggests that the deficits that gave way to the replicability crisis have also exposed weaknesses in the Daubert framework. These revelations have implications for both evidence that enters the courtroom through experts appointed by parties and through a judge's own fact-finding endeavors. Practically speaking, if judges, lawyers and jurors are not wary of replicability issues, bad science will almost certainly impact the legal process. I end with a few tentative prescriptions for how the law might evolve in light of the replicability crisis.

\section{Scientific Evidence in the Courtroom: From Frye to Daubert}

Daubert has been described as the "foundational opinion" in the field of scientific evidence and the law (Cheng \& Yoon, 2005, p. 471). The Daubert Trilogy represents the juristic standard for the admission of scientific evidence in federal and many state courts in the U.S. (Bernstein \& Jackson, 2004), and is binding in Canada as well (see Goudge, 2008; $R v$ Mohan; $R v J L J$ ). In Daubert, the Supreme Court modified the standard for the admission of scientific evidence formerly found in Frye v United States ("Frye"; 1923). Frye required an inquiry into whether a scientific finding or practice had reached general acceptance in the scientific community, asking if it was "sufficiently established to have gained general acceptance into the field in which it belongs" (Frye, 1923, p. 2796).

\section{The Daubert Analysis}

The court in Daubert overhauled Frye, requiring judges look not only at general acceptance, but into the reliability of the scientific evidence itself. Daubert offered four factors potentially useful in assessing the scientific validity of proffered evidence: (1) the testability of the scientific knowledge; (2) peer review and publication of the evidence; (3) the error rate associated with the evidence, and; (4) the general acceptance of the finding or practice (Daubert, 1994, p. 2797). In the second of the Daubert Trilogy, the court in Joiner confirmed that in a Daubert analysis, a court is free to assess the expert's opinion, the data supporting it, and the connection between the two (Joiner, 1997, p. 143). The court also held that a trial judge's application of Daubert should be reviewed on the "abuse of discretion" standard (Joiner, 1997, p. 142). This high standard makes it difficult for appellate courts to overturn a trial judge's decision to admit expert testimony, placing increased importance on this decision at first instance. The Supreme Court then elaborated in Kumho, stating that the Daubert factors applied to technical expertise as well, and that they should be considered a flexible and nonexhaustive set of considerations (Kumho $v$ Carmichael, 1999, p. 1179).

Adoption of Daubert remains a live issue at the state level. Although many state courts have adopted Daubert, several have expressly rejected it for Frye (e.g., California, Michigan, and New York). And among those state courts that have adopted Daubert, several have not adopted the full trilogy. For instance, many states have adopted Daubert and Joiner, but not Kumho (Bernstein \&
Jackson, 2004). As facts arise that engage various elements of the trilogy, it can be expected that its adoption will continue to be fought at the state level because of the general consensus that Daubert represents a stricter standard (Sanders, Diamond, \& Vidmar, 2002).

Indeed, Daubert adds three factors to bolster general acceptance, which was held over from Frye. The peer review and publication factor was added because ". . . submission to the scrutiny of the scientific community is a component of 'good science,' in part because it increases the likelihood that substantive flaws in the methodology will be detected" (Daubert, 1994, p. 2797). The testability factor has been interpreted to mean both whether a question can be scientifically falsified, and whether the evidence has been subjected to proper research methods, including the internal and external validity of the studies (Beecher-Monas, 1998). Finally, the error rate factor can encompass a variety of statistical means of supporting a scientific technique or finding (Beecher-Monas, 1998, p. 71; Faigman \& Monahan, 2009, p. 13). Again, Daubert is widely considered to represent a move from deference to general acceptance of scientific findings, to judicial review of the validity of the science itself.

\section{Frye and Daubert: The Role of the Trial Judge}

Spanning an array of issues applicable to the sciences, law, and the philosophy of science, there is no shortage of academic treatment of Daubert (e.g., see Beecher-Monas, 1998; Faigman, 1999; Cheng \& Yoon, 2005). Indeed, in asking judges to evaluate the quality of science, Daubert inspires questions regarding the very nature of scientific inquiry. These questions are generally beyond the scope of this essay, which is a more discrete inquiry into the failure of specific scientific safeguards and practices, how such failures can lead to findings that are difficult to replicate, and how this should inform law's treatment of scientific evidence. This conceptualization of the scientific method is perhaps best encapsulated by a view that discriminates between good and bad science as differences in degree, rather than kind (Lilienfeld \& Landfield, 2008; Lilienfeld, Lynn, \& Lohr, 2004). In fact, following from this view, Lilienfeld and Landfield's (2008) indicia of pseudoscience (as compared to science) have interesting reflections in the sources of the replicability crisis. For instance, just as pseudoscience often seeks to evade peer review (Lilienfeld et al., 2004, p. 6), we shall see that impoverished peer review helped contribute to the replicability crisis. With this in mind, I now describe how Daubert's innovation was treated by academics.

The immediate reaction within academia to Daubert was divided over whether it would prove a more discerning standard than its predecessor (see Chesebro, 1994 for a review). For example, in a series of toxic tort cases prior to Daubert, courts had applied Frye quite rigidly, excluding evidence deemed too novel to have reached general acceptance (Christophersen $v$ Allied-Signal Corp, 1991; Sterling v Velsicol Chem. Corp., 1988). This prompted academics to worry that the additional factors in Daubert added flexibility and would ultimately soften the standard (Chesebro, 1994).

Other commentators greeted Daubert warmly. Beecher-Monas (1998), for example, suggested Frye was too easily abused as it was not difficult to assemble enough experts to demonstrate general acceptance. She also found that several courts initially applied 
Daubert in a scientifically sophisticated manner, going beyond mere acceptance to cogently examine the methods and data analysis of the proffered evidence. In support of her argument, Beecher-Monas noted that a Daubert analysis of evidence regarding the social psychology of coerced confessions was well-applied (United States v Hall, 1997). Still, some researchers have argued that the impact of a jurisdiction's decision to adopt Daubert over Frye is limited by the scientific fluency of legal actors.

Research regarding the capability of judges, lawyers and jurors of understanding and applying the scientific concepts that underlie the Daubert test (see McAuliff \& Groscup, 2009 for a review) has yielded less than promising results. These results converge with well-established findings indicating human cognition is susceptible to several biases that may interfere with reasoning about science (e.g., see Kahneman \& Tversky, 1973; Likwornik, 2011). With regard to judges, Gatowski (2001), performed a survey study finding many showed a lack of scientific understanding of the error rate and testability concepts, but moderate to strong understanding of peer review and general acceptance. Judges seemed to also prefer the traditional Frye analysis with $42 \%$ of judges choosing general acceptance as the most important factor (Gatowski, 2001, p. 448).

Using experimental methods, Kovera and McAuliff (2000) measured the admissibility decisions of Florida circuit court judges in response to expert testimony that the experimenters had manipulated to reflect different aspects of Daubert. Depending on condition, the expert testimony was purportedly either published in a peer reviewed journal or not, and contained varying levels of internal validity (e.g., a missing control group). The results were once again discouraging in terms of the judges' use of components of the Daubert framework. Lack of internal validity and publishing appeared to have little or no effect on the judge's decision to admit the evidence. And moreover, less than $15 \%$ appeared to notice the flaws with regard to internal validity when they were present.

Similar research has been performed assessing the way lawyers (described in McAuliff \& Groscup, 2009) and jurors (Kovera, McAuliff, \& Hebert, 1999; McAuliff, Kovera, \& Nunez, 2009) assess scientific evidence with results in line with the findings on judges. With regard to lawyers, Kovera and McAuliff (described in McAuliff \& Groscup, 2009) utilized the same materials and methods as with the above study on judges, finding converging evidence that lawyers were unmoved by the internal validity and peer review factors when deciding to file a motion to exclude expert testimony. They report that lawyers did, however, appear attentive to the publishing factor, rating such findings as more reliable.

Jury-eligible individuals asked to evaluate scientific evidence were mostly insensitive to internal validity and peer review, although they did seem to give less weight to research lacking a control condition (McAuliff, Kovera, \& Nunez, 2009). In a different study, Kovera, McAuliff and Hebert (1999) found that juryeligible university students viewing a simulated trial partially based their decision making on the publication status and ecological validity (i.e., the fit between the participants in the study and the parties to the dispute) of the scientific evidence when evaluating it.

The above research is pessimistic regarding the scientific fluency of judges, lawyers, and jurors. Still, this is a field in its infancy and researchers readily admit that it is limited in both its quantum and the methodologies used (McAuliff \& Groscup, 2009, p. 31). For example, the data from the McAuliff and Kovera research program were largely culled from the context of litigation arising from workplace disputes. Moreover, some research suggests that there are ways to frame statistical concepts in a manner that is more easily digested by nonscientists (Cosmides \& Tooby, 1996). After a discussion of the replicability crisis, I will review specific avenues that present hope in bridging the divide between law and science.

In addition to research focused on scientific fluency, other work has examined trends in state and federal courts, because as established above, several states have refrained from adopting Daubert. This research has generally found little to no effect of Daubert on admission decisions. For example, in the context of criminal cases, Groscup, Penrod, Studebaker, Huss, and O'Neil (2002) found state adoption of Daubert did not affect admission rates. Moreover, Cheng and Yoon (2005) report data suggesting that state court adoption Daubert over Frye matters little because it does not seem to impact litigant behavior.

As I shall explain below, concerns with the ability of judges to apply Daubert effectively may be corrected by a multitude of measures, such as court-appointed technical advisors and improved judicial training on scientific topics. The replicability crisis, however, presents a novel and distinctive type of threat. In particular, it suggests that several generally accepted practices have long lagged behind best practices. This phenomenon has subtly affected - to its detriment-how science is performed and communicated. Fortunately, equipped with an awareness of replicability issues, initiatives designed to improve Daubert's application have a high likelihood of success. Prior to elaborating on this notion, a brief primer on the replicability crisis is useful.

\section{Replicability Crisis Overview}

Concerns with flaws in the research and publication process in the sciences are far from new, with several calls for change having been made over the years (e.g., American Psychological Association, 2009; Cohen, 1994; Wilkinson, 1999). The present crisis, however, is notable both for the sheer amount of research it has inspired plumbing its depths and causes, and for the tangible change it has inspired. Both have significant implications for the law's treatment of scientific evidence. While I will focus on the replicability crisis as it was felt in psychology, it must be noted that it is certainly not limited to psychology (e.g., see Ioannidis, 2005). The focus on psychology is partially one of convenience-psychological scientists have been especially concerned with the issue (Yong, 2012b) and have produced a great deal of empirical work examining the crisis (see Pashler \& Wagenmakers, 2012 for a review). Furthermore, most of the discussion will focus on the processes underlying the replicability crisis as projects have only begun to identify unreplicable findings with sufficient certainty (but see a promising start by Klein et al., 2013).

It is difficult to say exactly when the replicability crisis began. Some writers (Funder et al., 2014) trace it to an article by Ioannidis (2005) titled "Why Most Published Research Findings are False." In this article Ioannidis provided quantitative models indicating a high likelihood that many well-accepted studies are in fact false. Following the Ioannidis paper, several high-profile discoveries converged to cast a great deal of doubt on the efficacy of research and publication standards. These doubts culminated in the past 2 
years with a special edition of a leading journal devoted to the crisis (Pashler \& Wagenmakers, 2012) and new nonbinding guidelines from the Society for Personality and Social Psychology (SPSP; Funder et al., 2014). Journals have followed suit with changes in the editorial policy of such high-profile academic outlets as Nature (Editorial, 2013), Science (McNutt, 2014), and Psychological Science (Eich, 2014).

Work by Vul, Harris, Winkielman, and Pashler (2009) found that correlations in a burgeoning area of research that uses fMRI to study social psychological processes were higher than would statistically be expected given how the measurements were taken and analyses performed. Briefly, the source of the problem appears to be that experimenters naively obtained measurements in a nonindependent manner. In particular, several studies in Vul and colleagues' review based their analysis on fMRI measurements that had been selected because they met a threshold determined by the experimenters. In other words, these measurements were chosen due to their relation to a variable of interest rather than in the independent manner that their statistical analyses assume. The results were, therefore, biased in favor of finding a statistically significant result when one did not exist. Following the controversy caused by the Vul and colleagues (2009) article, a number of issues with the scientific process were highlighted in the media.

Notably, in 2010, the New Yorker published an article titled "The Truth Wears Off." It presented a description of the "decline effect" and its impact on several lines of research (Lehrer, 2010). The decline effect, as the name suggests, is a phenomenon in which effect sizes (i.e., the magnitude of the observed difference between an experimental condition and a control condition) of scientific findings will sometimes decrease over time. This article focused on the declining size of an eyewitness memory phenomenon called verbal overshadowing. Verbal overshadowing is the finding that when one verbally describes a face, he or she tends to be less accurate in correctly identifying that face in a lineup afterward, relative to someone who did not describe it (Chin \& Schooler, 2008). Lehrer noted that between 1990 and 1995, the size of the verbal overshadowing effect dropped by $30 \%$, and then another $30 \%$ in the following years. This account accords with a meta-analysis (i.e., a statistical review of published and unpublished data) performed by Meissner and Brigham (2001), which saw the effect downgraded from a medium to small effect size. During this time other media outlets reported additional anecdotal difficulties with replication (e.g., Bower, 2012a; Yong, 2012b).

Media attention coincided with the discovery of scientific fraud perpetrated by a well-respected social and cognitive psychologist. In August, 2011, an investigation determined that at least 34 of Diedrick Stapel's published studies were based on wholesale data fabrication (Stroebe, Postmes, \& Spears, 2012, p. 670). The scandal did little to improve psychology's public image. For example, Benedict Carey writing for the New York Times commented that the Stapel incident ". . . exposes deep flaws in the way science is done in a field ..." (Carey, 2011). Media attention stemming from the replicability still continues (e.g., see Johnson in the New York Times, 2014).

An additional high-profile case of reproducibility issues occurred when Daryl Bem published an article in social psychology's flagship journal presenting nine experiments with over 1,000 total subjects supporting the existence of ESP (Bem, 2011). Bem temporally reversed the order of several classic psychological studies, finding that experimental manipulations that would occur later in the study impacted present behavior. These highly implausible findings attracted a great deal of attention both within and without the scientific community. Many took this apparently strong evidence for ESP as a sign that current standards for reporting data were insufficient.

Wagenmakers, Wetzels, Boorsboom, and van der Maas (2011) responded to the Bem paper, suggesting several reasons Bem may have achieved false positives in eight of the nine studies (p. 426). These researchers first noted that many of the analyses in the ESP paper were exploratory, rather than confirmatory. Exploratory research derives not from a priori hypotheses, but from a look at the data itself. Wagenmakers and colleagues point out that exploratory practices increase the chances of false positives, and should only be used if they are followed with confirmatory research. They found several indications of exploratory research in the Bem paper (Wagenmakers et al., 2011). Subsequent attempts at reproduction failed to replicate Bem's findings (Galak, 2012; Ritchie, Wiseman, \& French, 2012; Robinson, 2011).

After these highly visible (but largely anecdotal) examples of scientific dysfunction, psychology responded with a freshet of systematic work examining how such failures could be possible, and how prevalent they are (e.g., Pashler \& Wagenmakers, 2012). Correspondingly, journals and governing bodies took steps to address the crisis (e.g., Funder et al., 2014). In the subsequent section I will review the sources of the replicability crisis with the Daubert factors as an armature for my analysis.

\section{Sources of the Replicability Crisis, Through the Lens of Daubert}

The issues that contributed to the replicability crisis in science pose problems for Daubert. While the Daubert does provide a coherent framework for evaluating a scientific finding, I will demonstrate that the Daubert court made assumptions about the scientific practices underlying that framework that have, in some cases, been violated. In particular, generally accepted practices for testing, error reduction, and peer review have at times not tracked best practices. In this section, I review the Daubert factors in light of the lessons learned from the replicability crisis. Most attention will be paid to testability and error rates, as those represent Daubert's primary innovations.

\section{General Acceptance}

A chief concern among critics of Frye's general acceptance standard was that by deferring the evaluation of scientific evidence to expert consensus, it represented little more than an exercise in nose counting (Faigman \& Monahan, 2009). In other words, general acceptance opens up the possibility that a technique or result, although generally accepted in a field, had not been rigorously subjected to the scientific method. Lessons from the replicability crisis bolster these qualms with general acceptance.

The replicability crisis was made possible by the failure of generally accepted practices to track best practices. Indeed, the concerns brought up during the replicability crisis can be traced back for decades. For example, as shall be discussed in greater depth below, use of overly simplistic and misleading statistical procedures were decried consistently by experts (e.g., Cohen, 
1994). These concerns were eventually echoed by an American Psychological Association Task Force (Wilkinson, 1999) with explicit recommendations for overhauling statistics in psychological research. The very same recommendations are being made once again in reaction to the replicability crisis (Funder et al., 2014).

The pattern of recommended change and subsequent disregard for these prescriptions illustrates that generally accepted practices do not always reflect best practices. A useful parallel may be found in transnational law where there is often a lag between nonbinding norms and their adoption by binding and enforceable agreements (e.g., the U. N. Convention on Corruption's adoption into the World Trade Organization General Procurement Agreement). Commentators have suggested that the problem in science may stem from a publication system that prioritizes style over substance (Bakker, van Dijk, \& Wicherts, 2012). Regardless, it is a story that reaffirms the need for a legal standard that goes beyond general acceptance. Unfortunately, as argued below, the replicability crisis demonstrates that flaws in generally accepted practices can, in some circumstances, contaminate the way science is performed and disseminated (i.e., the other three Daubert factors). Therefore, even a wary judge or scientist will have trouble determining which findings are dependable and which are not.

\section{Publication and Peer Review}

To quote Daubert, the rationale behind the publication and peer review factor is: ". . . submission to the scrutiny of the scientific community is a component of 'good science,' in part because it increases the likelihood that substantive flaws in the methodology will be detected." (Daubert, 1994, p. 2797). In other words, this factor seeks to screen scientific evidence by considering whether the science has been disseminated and vetted. The replicability crisis demonstrates that peer review and publication is problematic because it is subject to generally accepted practices that have long lagged behind best practices. For example, peer review has traditionally not required that raw data be subjected to the peer review process, a system that allows researchers a great deal of latitude in how they analyze and present their data. What follows describes some of these issues with peer review and publication that contributed to the replicability crisis.

Lack of access to raw data. Researchers believe that lack of access to raw data played a part in the replicability crisis (Funder et al., 2014). In other words, statistical analyses could not be vetted by methodologists because the raw data was not available. Contrary to what many would expect, journals have not always required that raw data be produced along with the report associated with it. Methodologists have long cried for such transparency, noting that the cases in which such a requirement would be unwieldy (e.g., proprietary data, privacy issues) are few and far between (Wicherts \& Bakker, 2012).

The lack of such a requirement would not be as detrimental if authors were forthcoming with their data when contacted. However, recent research (Wicherts, Bakker \& Molenaar, 2011) found that less than $50 \%$ of authors shared their data, despite multiple requests. Moreover, it was the authors with statistically weaker findings who declined to share. Simonsohn (2013) recently noted that access to data is extremely useful in ruling out benign explanations when results seem suspicious. Provision of raw data would help scientists do precisely what the court in Daubert thought peer review and publishing would achieve: assess scientific validity. Moreover, access to raw data would assist expert witnesses in creating a veridical picture of a scientific field to present to legal decision makers, rather than relying on the analyses performed by the authors of the work.

Publication bias. Another likely source of the replicability crisis is publication bias (i.e., a prejudice that can form in a body of knowledge when a certain type of result is preferred over another; Dickersin, 1990). One variety of publication bias is a bias toward publishing positive over negative studies. Indeed, it is well accepted that negative studies (i.e., those showing no statistically significant result) are often discriminated against, with positive studies (i.e., those showing an effect) predominating the literature (Fanelli, 2012; Sterling, 1959). In fact, literature reviews often must provide some kind of ad hoc correction for this phenomenon that is known as the file-drawer effect to indicate that negative studies are never seen outside the confines of the laboratory that produced them (Rosenthal, 1979). Despite such corrections, the file-drawer effect poses a serious problem for accurately assessing the true nature of a scientific finding. In other words, the peer review and publication process, by being biased toward positive results, allows for overestimation of the strength and robustness of a finding or method to reach general acceptance.

Empirical evidence supports the existence of a publication bias in scientific bodies of research. For example, Sterling (1959) examined four psychological journals during the course of a year and found that articles reporting data that failed to reject the null hypothesis comprised only $2.72 \%$ of the articles published. Several findings in other fields suggest that this is not an uncommon result (e.g., see Dickersin, 1987; Coursol \& Wagner, 1986). Research tracking the percentage of positive results across all fields finds the proportion has hovered around 90\% in recent years (Fanelli, 2012). Experimental evidence confirms such reports. For instance, Mahoney (1977) randomly assigned journal referees to read and evaluate articles that were subtly tweaked to contain positive or null results. He found that referees evaluating work with negative results not only deemed the overall paper to be less worthy of publication, but also rated the methods as less convincing-despite the fact that the methods sections of the papers were identical. These policies have a clear effect on authors. Greenwald (1975), in surveying a sample of psychological researchers, found that $41 \%$ reported they would seek to publish a positive finding, whereas only $5 \%$ would seek to publish a null result.

Ironically, by placing weight on peer review and publication, Daubert may indeed distract judges from bodies of unpublished work that contain valuable data (e.g., negative findings, successful and failed replications). In addition, recall that one of the few facets of the scientific process jurors are attentive to is the publication status of research (Kovera, McAuliff, \& Hebert, 1999). Even if unpublished research passes the judicial gatekeeper, there is worry that it will be undervalued by jurors. The following section suggests other ways in which publication and peer review may be misleading to judicial actors.

Valuing novelty over rigor. A focus on novel and exciting results and corresponding lack of attention to methodology in the peer review and publication process has been implicated as a source of the replicability crisis (Giner-Sorolla, 2012). The changes Nature is making to its review process illustrates the 
problem. In fact, Nature has explicitly admitted the journal's role in the replicability crisis:

The problems arise in laboratories, but journals such as this one compound them when they fail to exert sufficient scrutiny over the results that they publish, and when they do not publish enough information for other researchers to assess results properly. (Editorial, 2013, p. 398)

The journal Psychological Science has made similar admissions. In response to the replicability crisis, this journal recently revised its word limits, exempting methods and results sections from the limit. This monumental change was followed with the commentary:

The intent here is to allow authors to provide a clear, complete, self-contained description for their studies, which cannot be done with restrictions on Method and Results (Eich, 2014, p. 3; emphasis is my own)

Similar changes can be found in new guidelines being produced by professional organizations. For instance, SPSP's Task Force on Publication and Research Practices recommendation 4 reads:

Include in an appendix the verbatim wording (translated if necessary) of all the independent and dependent variable instructions, manipulation and measures. (Funder et al., 2014, p. 8)

These explicit and implicit admissions that previous practices were giving insufficient attention to methodology are troubling from a legal standpoint. In particular, according to Daubert (1993), a trial judge's gatekeeper role focuses "... solely on the principles and methodology; not on the conclusions they generate" (p. 1797). One wonders how well the publication and peer review factor can signal that a methodology has been reviewed if that methodology is not made fully available to reviewing scientists. And further, how should a gatekeeper assess methodology if only the publishing scientist is privy to that information?

Complicating the matter are initiatives designed to both make science more readily accessible, but lack a substantive peer review component. One example is the relatively recent phenomenon of open access journals. These academic outlets are unlike standard academic journals in that they are not situated behind pay walls and are open to the public to access and, ostensibly, to critique. They rest on an economic model by which authors pay the costs of publication. These journals should have the effect of allowing traditionally nonpublishable data to see the light of day. The downside is that the level of peer review at these journals seems to be substandard in many cases. For instance, Science recently published a finding indicating that over $50 \%$ of open access journals were willing to publish a "bait" study they had submitted with serious errors of design and data interpretation (Bohannon, 2013). Open access journals therefore may assist courts insofar as they make more data available. But at this point, deference to the review process at these journals may be problematic. ${ }^{3}$

It has been noted before that peer review and publication does not necessarily lead to research that is beyond reproach (e.g., Faigman \& Monahan, 2009; Jasonoff, 1996). The replicability crisis demonstrates that this issue may be more serious than previously thought. For one, despite the Daubert court's apparent belief that methodology would be well vetted (i.e., a close review of the design, variables studied and how the data was analyzed), methodological review has been lacking. This phenomenon has been documented in the past, with critics lamenting a shift from a more fulsome methods-orientated science reporting to the current results-driven model (Dickersin, 1990). These are precisely the issues Nature and Psychological Science recently grappled with, deciding that its existing review process did not look deeply enough into methodology. While these changes are welcome, the tacit admission that previous guidelines were lacking is troubling for Daubert's peer review and publication factor. Going forward it will be important that these new practices be imported into how the legal field treats scientific evidence.

\section{Testability and Error Rates}

The sources of the replicability crisis also indicate that the testability and error rate factors are of less use than originally thought. In theory, analyzing whether and how a finding or method has been tested should allow judges to readily weed out results that are not sufficiently reliable. These concepts were presented in a somewhat nebulous manner in the Daubert Trilogy (Faigman \& Monahan, 2009). In addition, there is also a worry that such a task is beyond the scientific competence of judges (Gatowski, 2001). While this concern may be rectified by training and the use of court-appointed experts in complicated cases, the replicability crisis presents a more fundamental concern. In particular it poses the problem that the testing and error rate standards used by scientists themselves have sometimes proven insufficient. Below I will discuss these issues, including how research has traditionally been designed and how results have been analyzed.

Questionable research practices. Questionable research practices (QRPs) do not reach the level of fraud and were seldom discussed prior to the replicability crisis. They represent a gray area in acceptable scientific practice, and are likely a significant cause of replicability issues in science (Funder et al., 2014, p. 5; John, Loewenstein, \& Prelec, 2012). QRPs can substantially bias results published in the scientific literature. Simmons, Nelson, and Simonsohn (2011) identified several QRPs that are actively used by researchers. They include: strategically deciding when to stop collecting data (i.e., continuing to collect data until the effect has reached statistical significance), using multiple types of measurement but only reporting the successful ones, and failing to disclose experimental conditions in the final report. Simmons et al. (2011) performed thousands of simulations to determine the effect of QRPs on the prevalence of false positives. They found that use of all QRPs would cause false positives in Experiments $60 \%$ of the time.

Beyond simply demonstrating that QRPs can be used to both gain an advantage and introduce false positives into the scientific literature, additional research suggests QRPs are indeed widely used. John and colleagues (2012) performed an anonymous survey of 2,155 research psychologists, asking about their use of QRPs. Over $60 \%$ of respondents admitted to selectively reporting a study's measurements and over $45 \%$ said they selectively reported

\footnotetext{
${ }^{3}$ There are, however, open access journals (e.g., PLOS ONE, cited numerous times in this essay) that routinely engage in demonstrably high levels of peer review.
} 
studies that worked. A further $38 \%$ reported deciding to exclude data after looking at the impact it would have on the final results (John et al., 2012). Such use of QRPs is probably explained by the fact that prior to the replicability crisis, QRPs were seldom openly discussed, and likely advantageous to a scientist's career. Indeed, a simulation by Bakker and colleagues (2012) finds that the optimal "strategy" in successfully publishing involves employing several small, underpowered studies rather than one large one, and reporting the first one that works. These sobering findings suggest that not only can QRPs bias science, they do, and at a level higher than most predicted.

The implications for Daubert's testability factor are immense. Daubert's innovation rests on the notion that bad science may be weeded out by asking judges to go beyond general acceptance and evaluate the science itself. But considering that QRPs go nearly undetectable in the published science, there is little to no chance of picking them up under testability. Moreover, considering scientists themselves only recently addressed the issue, it is unlikely that judges would fare any better. This once again illustrates the notion that deficiencies in general accepted practices permeate the rest of the Daubert factors, rendering their utility dubious at times. But it is important to note that this conclusion is not fatalistic- the tools exist to manage to QRPs.

Scientists, and psychological scientists in particular, have been laudably proactive in attempting to curb the use of QRPs. As mentioned above, QRPs are now being extensively researched and warned against (Pashler \& Wagenmakers, 2012). Prominent researchers and methodologists have provided recommendations to curb QRPs, notably prespecification of research methodology (e.g., Cumming, 2014, p. 4; Schooler, 2011). For example, millions of dollars have been pledged to the Open Science Framework (Open Science Collaboration, 2012), which provides, among other initiatives, an online database for researchers to register experiments before they are performed, thus reducing the chance that important measurements go unreported. Such preregistration has long been mandated in clinical research, but remained optional in other scientific fields.

New publication standards have given teeth to the above norms. Beginning in 2014, scientists seeking to publish in Psychological Science are required to complete a 4-item checklist developed based on the norms established by Etienne LeBel and colleagues' PsychDisclosure platform (http://psychdisclosure.org). This checklist involves confirming that the author reported all of the measurements and experimental conditions. It also requires the researchers report all of the excluded data and the reasons for any such exclusion. While this measure still places trust in the experimenters, its binding nature represents a significant step forward in science's commitment to curbing QRPs.

In addition to the mandatory disclosure provisions above, Psychological Science has also adopted-although noncompulsorily - the suggestions of the Open Science Framework. In particular, the Open Science Framework has proposed awarding various "badges" for studies opting to make their data and materials publicly available, as well as for preregistering the study. As mentioned above, preregistration is a powerful means of reducing QRPs, as it would provide a record of a study's design and methods prior to it being performed and reported, allowing scientists (and potentially judicial actors) to confirm that all conditions or measures were reported. There are, of course, types of research where preregistration is not practical, a scenario that Psychological Science's systems makes allowances for (Eich, 2014, p. 3). Preregistration also addresses the file-drawer effect (reviewed above) by providing a record of studies that, for one reason or another were not published, but may provide some practical or theoretical importance. The badge system, although not mandatory, should motivate researchers to be more open in their practices.

Lack of replication. "Confirmation comes from repetition. Any attempt to avoid this statement leads to failure and more probably to destruction." (Tukey, 1969, p. 84)

Few within science would dispute the above quote. Indeed, replication is commonly referred to as the sine non qua of scientific research (e.g., see Funder et al., 2014). Unfortunately, despite widespread acknowledgment of its importance, replication is uncommon in general practice. For instance, a recent study of a random sample of published research containing the term replication found that only $1.07 \%$ of psychological studies are replicated (Makel, Plucker, \& Hegarty, 2012, p. 537). While this finding paints a dim picture of the state of replication in the psychological sciences, the state of affairs in other disciplines is no brighter. For instance, John Ioannidis notes a low level of replication in other scientific disciplines and finds that medical studies often show initially stronger results that regularly prove irreproducible (Ioannidis, 2005a).

One defense of the present regime is that while direct replications (i.e., a more-or-less exact duplication of a previous study) are uncommon, conceptual replications are relatively frequent. For example, Lykken (1968) suggested that conceptual replications (he termed them "constructive") have a great deal of value in elucidating the construct behind the data. Indeed, conceptual replication involves testing the underlying theory of a study with different methods. For example, a conceptual replication of verbal overshadowing might test whether verbalization impairs memory for other experiences, such as taste or smell. The Makel and colleagues (2012) study cited above found that of the replications they did find, about $82 \%$ were conceptual with the remainder being direct or a mix of the two. While conceptual replication may seem to bolster the believability of a finding, Pashler and Harris (2012, pp. 531, 534) suggest it may have what they term "pathological results."

In analyzing direct versus conceptual replications, Pashler and Harris (2012) note that published failed direct replications go a great ways toward increasing understanding of a phenomenon. And even if they are not published, informal channels may help spread the word. Successful conceptual replications, on the other hand, are very likely candidates for publication with unsuccessful ones easily written off as simply pushing the theory too far. It then becomes tempting to publish small conceptual replications and not report the failed ones, thus giving the community the impression a phenomenon is robust. Pashler and Harris (2012, p. 533) therefore conclude that ". . . entire communities of researchers in any field where direct replication attempts are nonexistent and conceptual replication attempts are common can easily be led to believe beyond question in phenomenon that simply do not exist."

The lack of direct replication is likely a result of lack of incentive. As reviewed above, novelty has long been rewarded in the publication process, and replications are by definition, not novel (Giner-Sorolla, 2012). The most common defense for novelty is that if it is wrong, the science will self-correct (Aronson, 
1977, p. 192). Indeed, in a paper comparing legal and scientific values, Gastwirth (1992, p. 56) writes, "Unlike the Frye doctrine, science encourages novel experiments and theories because unexpected findings will be reexamined by independent researchers." The empirical evidence reviewed above suggests Gastwirth may have been mistaken as replication has traditionally not been the norm.

As quoted above, confirmation comes from replication. And, above all else, legal decisions depend on accurate input (i.e., evidence). Given the lack of replication of scientific research, it is therefore challenging for judicial decision makers to come to an accurate understanding of some scientific findings and methods. Once again, this does appear to be changing with strong recommendations coming down from scientists and professional bodies encouraging replication. For instance, recommendation six of the SPSP Task Force reads, "Encourage and improve the availability of publication outlets for replication studies." (Funder et al., 2014, p. 6)

\section{New Statistics.}

Null-hypothesis significance testing (NHST) has long been the mainstay method of analyzing data and drawing inferences in psychology and many other disciplines. This is despite the fact that, for nearly as long, researchers have recognized essential problems with NHST in general, and with the dichotomous ("significant vs. nonsignificant") thinking it engenders in particular Eich (2014, p. 5).

Despite a great deal of criticism, much of psychological science and other disciplines continue to rely on NHST as its default method of quantitative argument. In short, NHST allows for the calculation of the conditional probability of the observed data, assuming that the null hypothesis is true. Researchers often set the null hypothesis as the hypothesis that the relationship between two variables is zero. So in other words, null hypothesis significance testing returns the likelihood of the observed data, assuming that in reality there is no effect. This probability is known as a " $p$ value."

Many have questioned the logic and intuitiveness of NHST over the years (e.g., Carver, 1978; Kirk, 2003). For instance, see the following well-cited passage from Jacob Cohen (1994, p. 997):

What we want to know is "Given these data, what is the probability that [the null hypothesis] is true?" But as most of us know, what the obtained $p$ value tells us is "Given that [the null hypothesis] is true, what is the probability of these (or more extreme) data?"

Problems with the interpretation of NHST has led both pre(Wilkinson, 1999) and postreplicability crisis (Funder et al., 2014) professional bodies to recommend a more fulsome set of statistical procedures. Psychological Science has endorsed one particular set of procedures called "New Statistics" (Cumming, 2014), which represents a movement from NHST to actual estimates of values in question as well as other complementary measures.

One complementary measure of particular use is "statistical power." Calculating and reporting statistical power is, in fact, the first recommendation of the SPSP Task force (Funder et al., 2014). Statistical power represents a study's likelihood of rejecting the null hypothesis (i.e., finding an effect), when the null hypothesis is indeed false. In other words, a study with a high degree of statistical power that fails to reject the null hypothesis provides information concerning whether there is indeed no effect because it could have found that effect.

Commentators have suggested that running sufficiently powered studies should help curb QRPs (Funder et al., 2014, p. 5). Further, as reviewed above, both law and science are interested in not only the presence of an effect, but the absence. Power helps indicate whether or not a negative finding is indicative of anything at all. In addition, lack of power is associated with several other undesirable results. For example, in what is known as the "winner's curse" phenomenon, low-powered studies tend to overestimate the size an experimental effect (Button et al., 2013). The winner's curse is caused by the fact that low-powered studies are only capable of uncovering effects that happen to be aberrantly strong. The winner's curse, therefore, results in bias in the publically available data indicating an effect is stronger than it is. Statistical power is not explicitly encapsulated by either the testability or error rate factor, but is an important concept in evaluating the meaning of scientific findings.

Requirements surrounding statistical measures are notoriously difficult to implement as statistics is essentially a form of principled argument (Abelson, 1995), and thus open to multiple interpretations. Still, Psychological Science now requires, as part of the checklist described above, that researchers explain how they determined the sample size they used. This determination will frequently involve some discussion of statistical power-indeed, a welcomed advance.

\section{Scientific Evidence in a Postreplicability Crisis World}

If there is one theme to be extracted from the above analysis, it is that the replicability crisis revealed a weakness in the Daubert framework. The risk with a general acceptance standard was always that nose counting can, at times, lead to inaccurate results because the consensus is wrong (Faigman \& Monahan, 2009, p. 5). In moving from general acceptance to an analysis of the validity of the science itself, the Daubert court did not consider that sometimes those scientific results themselves were the result of inadequate generally accepted practices. The replicability crisis rendered this point painfully salient, and it is one that has important implications for how courts should treat scientific evidence going forward.

\section{Frye or Daubert?}

Recall that several State courts have refrained from "Daubertizing," instead preferring Frye's general acceptance test. This stance is open to criticism on many accounts (e.g., see Faigman \& Monahan, 2009; Beecher-Monas, 1998). From a practical standpoint, however, existing scholarship suggests the difference may not matter much at all. For instance, limited scientific fluency among judicial actors likely restricts the effect that Daubert's more thorough analysis can have (McAuliff \& Groscup, 2009).

Lessons learned from the replicability crisis suggest that the Daubert standard is better equipped than Frye to ensure that good science reaches decision makers. As mentioned, the replicability crisis was made possible by deeply entrenched generally accepted practices that did not track with best practices. Frye, in probing general acceptance, does not easily get at best 
practices when such divergences exist. Moreover, identifying and correcting for replicability-related issues will require a more searching review of the science. Daubert at least provides a framework that can address the issues described in this essay. For instance, replication itself easily falls under the Daubert head of testing, and concepts from the "New Statistics" fit well under the error rates (Faigman, Monahan, \& Slobogin, 2014). Courts should ensure, however, that Daubert is employed in a manner that takes into account best practices for testing, error rates and peer review. Some preliminary suggestions for how this should be done follow a brief review of the impact of replicability issues on various ways scientific evidence may impact legal proceedings.

\section{The Replicability Crisis and Empirical Framework and Diagnostic Expert Testimony}

Within expert testimony, a distinction can be drawn between "empirical framework evidence" and "diagnostic evidence" (Monahan \& Walker, 1991; Faigman, Monahan et al., 2014). Empirical framework evidence is that which applies generally to the instant case, providing a context for judicial decision maker to understand an issue at trial. Diagnostic evidence, on the other hand, concerns an application of science to the specific facts of the case. In other words, empirical framework evidence can demonstrate that an effect occurs in the population, whereas diagnostic evidence can demonstrate that it applies to the instant case.

An example is useful in making this distinction between empirical framework and diagnostic evidence more concrete. Much has been written about the hypothetical situation in which fMRI methods are used to detect lies in a legal context (e.g., Schauer, 2010). In this case, an expert providing framework evidence might describe research showing that on average, the brain activity of those lying looks reliably different under an fMRI scanner than those telling the truth. An expert providing diagnostic evidence, however, would be asked to say, based on an fMRI scan, if a particular party was lying. This distinction has proven remarkably useful in elucidating different issues that arise in the context of different types of evidence (Faigman, Monahan et al., 2014). This is no less true for the present essay.

The replicability crisis is especially problematic for framework evidence. It has been noted elsewhere that with regard to framework evidence, the question of testability is complicated by the variety of methods that can be used to establish a relationship between variables, resulting in a difficult consideration of the weight of the totality of the evidence (Faigman, Monahan et al., 2014 , p. 31). The issues brought up by the replicability crisis complicate this calculus.

The replicability crisis indicates that even noble attempts at surveying a scientific literature with weight placed on findings from well-controlled studies vetted by a prominent journal can lead to miscalculations. For example, even a well-meaning examination of the basic research surrounding fMRI lie detection research, and the academic research linking such research to law (e.g., Schauer, 2010; Stoller \& Wolpe, 2007) would have-prior to the replicability crisis-missed a major statistical issue with such research. In particular, recall that Vul et al. (2009) noted that many such studies may underreport their error rates due to statistical issues with multiple nonindependent measurements. These issues with basic research can be linked to the peer review issues reported above regarding a lack of attention to methodology and corresponding lack of quantitative experts serving as peer reviewers.

QRPs also pose a potential problem for framework evidence. It has been noted that " $[w]$ ithout error rate information Daubert's command that courts evaluate the reliability of expert evidence cannot be accomplished, at least when empirical framework is involved" (Faigman, Monahan et al., 2014, p. 36). The multiple ways in which error rates can be measured and conceptualized (e.g., $p$ values stemming from NHST, confidence intervals, effect sizes) already presents a challenge for judges. The difficulty with QRPs is that they seriously affect the interpretability of any metric of error rate. With respect to the fMRI lie detection example, ${ }^{4}$ it would not be clear from research reported under prereplicability crisis standards what data or conditions were excluded from the final analysis, thus potentially inflating error rates. As will be suggested below, courts should be wary of QRPs, looking for external indicia of methods that prevent them, and asking experts to report about any conditions or measurements that did not make it to the final analysis.

Faigman, Monahan et al. (2014) note that the concepts of testability and error rate are not always "amenable" (p. 37) to the evaluation of diagnostic evidence. This is because diagnostic evidence is more concerned with the particular practices and experience of an expert applying a diagnostic technique. Still, framework evidence often provides a context for diagnostic evidence, and they often accompany one another. As such, replicabilityrelated issues will still most likely arise in many cases when diagnostic evidence is given, but more as a threshold matter.

Furthermore, in certain cases, diagnostic standards are girdled by bodies of clinical research that may be probed for replicabilityrelated concerns (Faigman, Monahan et al., 2014, p. 38). In fact, a great deal of debate exists over the extent that clinicians and diagnosticians should restrict their practices to that which is science or evidence-based (e.g., see Lilienfeld, 2002; Faigman \& Monahan, 2009, p. 22). Still, in many cases, issues stemming from the replicability crisis will be more pertinent with regard to framework evidence.

\section{The Replicability Crisis and Judicial Fact-Finding}

The replicability crisis also has implications for what have been termed "legislative facts." These types of facts are those that courts come to when making a decision that goes beyond the dispute at hand (Davis, 1942; Monahan \& Walker, 1991, p. 573). A widely cited (Larsen, 2013, p. 102; Monahan \& Walker, 1991, p. 572) example of legislative fact is Justice Brandeis' factual determination in Muller v Oregon (1908) that long working hours were detrimental to female laborers. This type of factual finding was later termed the "Brandeis Brief." Legislative facts may be con-

\footnotetext{
${ }^{4}$ This example is simply used for convenience. There are no indications I am aware of that such studies contain QRPs beyond concerns with science as a whole.
} 
trasted to "adjudicative facts," which are applicable only to the case at hand (Monahan \& Walker, 1991, p. 576). ${ }^{5}$

Compared to expert evidence proffered by parties to the dispute, the rules and norms concerning admissibility of judicially determined legislative facts are decidedly looser. Larsen (2013, p. 72) notes that legislative facts are explicitly exempted from the U.S. Federal Rules on Evidence and indeed advisory notes promote their unrestricted use. Legislative facts can come from a variety of sources, including amicus briefs and the judge's own fact-finding endeavors. These facts are regularly based on scientific and social scientific methods. One example is an fMRI study linking video games and aggression cited in Justice Breyer's dissent in Brown v Entertainment Merchant's Association (2011) that was subsequently criticized in the scientific community (Larsen, 2013, p. 70; Neuroskeptic, 2011).

Moreover, Larsen recently emphasized the increased precedential value of legislative facts. In particular, she noted that due to the increased ease of keyword searching decisions, it is increasingly easy for lower courts to discover factual findings and cite them as authority. Furthermore, because of the increased length of U.S Supreme Court decisions, there are more of these types of facts to cull from. Larsen argues that this trend presents a serious danger, as these findings of fact may represent a nonveridical portrayal of the science and motivated reasoning on the part of justices (Larsen, 2013, p. 101). In other words, increasing reliance on judicial fact finding can allow poorly vetted scientific finding to have an enduring effect.

Lessons from the replicability crisis are also pertinent for the increasing importance of factual precedent. These findings of fact, when informed by science, are prone to the same replicabilityrelated issues recounted above and may indeed hit harder in the case of factual precedents. For instance, the file-drawer effect is especially problematic. Recall that it is well established that the scientific literature is biased toward positive findings. Expert evidence may indeed provide a check on this phenomenon as the expert may know to refer to meta-analyses and contact his or her colleagues for unpublished work. It is comparatively unlikely that a justice or clerk will take these corrective measures. Building on this insight, the following section addresses several initiatives previously proposed to improve the legal treatment of scientific evidence, and how they may be best employed in light of the replicability crisis.

\section{Lessons From the Replicability Crisis}

As reviewed above, this essay is far from the first to remark upon the challenges raised as a result science's presence in the courtroom. This work, both empirical (e.g., Gatowski, 2001) and theoretical (e.g., Faigman \& Monahan, 2009; Larsen, 2013; McAuliff \& Groscup, 2009) is impressive not only for its rigor, but for the tangible recommendations it has produced. In particular, research suggests that court appointed experts, technical advisors, and scientific training for judges may be useful in allowing Daubert to reach its full effectiveness. After a brief review of these initiatives, I will discuss how they are informed by the lessons learned from the replicability crisis.

Improved scientific training and education for judges may improve the scientific fluency of judges and thus help ensure good science reaches juries (Faigman \& Monahan, 2009; Merlino, Dille- hay, Dahir, \& Maxwell, 2003). Such education could begin in law schools (Merlino et al., 2003) and progress through continuing education programs (Black, Ayala, \& Saffran-Brinks, 1994). In Canada, the "Goudge Report" was prepared in the wake of highly publicized cases of flawed forensic pathology affecting several decisions (Goudge, 2008). Recommendation 134 of the report (p. 502) coincides with the prescriptions from the U.S. experience, providing for training programs for judges on a variety of scientific safeguards and the Daubert analysis (p. 502). Finally, a wealth of excellent academic guidance is also available as a measure of judicial self-help (e.g., Faigman et al., 2014).

Researchers and commentators have also discussed greater use of court-appointed experts and technical advisors (Faigman \& Monahan, 2009; Berger, 1994; Gross, 1991) in assisting with the evaluation of scientific evidence. The use of court-appointed experts is expressly allowed by Federal Rule of Evidence 706 (2011b). In contrast to party-retained experts, the theory with court-appointed experts is that they are more likely to give a nonbiased perspective on the science to the jurors. Research is generally mixed over whether these experts tend to prove beneficial or are overly influential on juries (McAuliff \& Groscup, 2009). Moreover, there has been substantial judicial resistance to the use of court-appointed experts (Cecil \& Willging, 1993). Technical advisors, as compared to court-appointed experts, limit their assistance to judges on matters of scientific evidence. Despite initial misgivings (Faigman \& Monahan, 2009, p. 21; Goudge, 2008 , p. 506) concerning both court-appointed experts and technical advisors, there appears to be traction for both (Faigman \& Monahan, 2009, p. 21).

As an alternative or complement to court-appointed experts, safeguards and procedures surrounding party experts may be imposed. For example, in the context of criminal trials, the Goudge Report (2008, p. 509) recommends pretrial meetings between opposing experts that may help clarify points of consensus and difference. In such cases the report also recommends a code of conduct to be read and signed by expert witnesses acknowledging a duty to acknowledge the strength of the data supporting an opinion (Goudge, 2008, p. 504). Such procedures have been adopted in England and Wales ( $R$ v Harris, 2005).

In general, the measures above should be informed by lessons learned from the replicability crisis and stay current with the reforms going on within science. There is a serious risk that history will repeat itself and that several of the new norms and procedures developed in response to the replicability crisis will never be adopted in a binding manner in science. In that case, it would be up to judicial actors to adopt such safeguards. Fortunately, awareness of the replicability crisis can inspire initiatives that drill down into the aspects of good science that prevent replicability issues. The following recommendations largely follow initiatives that scientists have developed to address the replicability crisis, such as the Society for Personality and Social Psychology's new guidelines (Funder et al, 2013), editorial changes at Nature (2013) and the Open Science Framework (Open Science Collaboration, 2012).

\footnotetext{
${ }^{5}$ Faigman, Monahan, and Slobogin (2014) note that there can be considerable cross-over between legislative fact and adjudicative fact, instead preferring framework evidence for such material. Here, I focus on legislative facts determined outside of the context of expert testimony brought by parties to the instant case.
} 
In response to the replicability crisis, commentators have pointed to the importance of direct replication (Pashler \& Harris, 2012; Eich, 2014), or in other words: Has the finding been reproduced by an independent party? This observation has been made before in the legal context (e.g., see Faigman, Saks, Sanders, \& Cheng, 2008, p. 63) but the replicability crisis indicates that the distinction between direct replication and its cousins can be one that is easy to ignore-even for scientists. Still, prominent methodologists have long considered direct replication to be of hallmark importance in producing valid results (e.g., Cohen, 1994).

While guidance from treatises and professional bodies can certainly be helpful for judges, replication is one area where courtappointed experts can be of special assistance. For instance, direct replications-both those that fail and succeed-are notoriously difficult to publish. Court appointed experts or technical advisors with a background in the field in question would be well-placed to scour the field for evidence confirming or refuting the proffered evidence. Because they possess a background in science, court appointed experts would also be well placed to distinguish between direct and conceptual replications.

With a great deal of unpublished data in existence, as well as data from open-access journals that may not have been well vetted, there is danger of a judge being drowned in information. In situations such as these, appointing a technical advisor or expert may also be the most sensible choice, as such an individual may be better placed to evaluate a study's methodology and compile several experiments into a meta-analysis to get an idea of the effect size. In fact, meta-analyses have proven to be a useful tool both with respect to assembling information and facilitating understanding of a great deal of data (Schmidt, 1992). While meta-analyses are not without limitations (e.g., Stegenga, 2011), they represent an excellent topic for judicial training programs.

Another factor to consider, when possible, is the degree to which the experimenter disclosed, within reason, all of the variables and measurements he or she used. Openness regarding methodology and procedure is hallmark of good science (Lilienfeld \& Landfield, 2008). More specifically, such consideration would help screen out research containing QRPs. An excellent example is the aforementioned Open Science Framework, which provides an online database for researchers to register experiments before they are performed, thus reducing the chance that important measurements go unreported. There are, however, several other mechanisms available. The PsychDisclosure platform mentioned above also creates assurances that there were no substantive changes between conception of the experiment and its execution, with the option to provide reasons for any such changes. Furthermore, simple provision of data allows the scientific community to provide independent analysis (Simonsohn, 2013).

It would be relatively easy for training initiatives and guides to include information about the availability of preregistration systems (which it should be noted are already a well-accepted component of clinical medical research), and which journals have mandated or recommended them. Clearly, the presence or absence of preregisration is uninformative in the case of most prereplicability crisis research outside of the medical domain. But in a postreplicability crisis world, it is an important factor to engage an expert witness about. For example, the badge system, recently endorsed by Psychological Science provides an excellent, but optional, external indicum of openness of research methods. I don't expect these factors to be relevant in every case, but they are relatively easy to grasp concepts and if contemporary research failed all of these indicia of openness, it may raise red flags about the research.

Openness of research methods also impacts Daubert's peer review and publication factor. As reviewed above, research indicates that jurors do seem swayed by the publication status of research (Kovera, McAuliff, \& Hebert, 1999). Therefore it would be useful for judges to examine not just whether a study has been peer reviewed, but how that peer review was conducted. Once again drawing from the openness considerations, it stands to reason that a journal that has adopted such standards will have engaged in a higher level of vetting. On the other end of the spectrum, there is reason to think that the bad reputation some open access journals have for performing a cursory peer review process is a justified reason to discount their findings (Bohannon, 2013).

Daubert's peer review factor has been considered little more than a logical extension of general acceptance (Beecher-Monas, 1998). But as compared to testability and error rate, it is a factor that is easy to grasp by lay audiences. Ease of understanding cuts both ways, rendering peer review a factor that presents both a danger of overvaluation (Friedman, 2003), but one ripe for training initiatives. Indeed, guides and training programs prepared by academics but aimed at judges could easily convey information about the degrees of quality of peer review, including their demands for sharing of research material, data, disclosure and preregistration. It would also be simple and nearly costless to maintain an online database of various publications and the level of scrutiny they represent with regard to replicability concerns (e.g., those that have adopted postreplicability crisis measures, to those that failed to identify bait experiments such as in Bohannon's study in Science noted above).

On the other hand, it will not always be clear how thorough the peer review itself was. This is especially true with respect to the quantitative aspects of review. For instance recall Psychological Science made a statement embracing the statistical movement away from NHST (Eich, 2014). Further, Nature (Editorial, 2013) declared it would assign methodological and quantitative experts to review research when appropriate. While these declarations are important, they will be difficult to assess unless and until they are deployed in a transparent manner. At this stage of science's recovery from the replicability crisis, such mechanisms are not yet in place.

In light of the difficult to assess nature of statistics and methodology, in cases where such complicated issues arise, judges would be wise to be liberal in appointing a technical advisor or court-appointed expert. Moreover, in jurisdictions where procedural law allows for it, court-mandated pretrial meetings between party experts could be useful in honing in on these issues. In fact, research has demonstrated (Brown, Tallon, \& Groscup, 2008, described in McAuliff \& Groscup, 2009) that when specifically instructed to educate the jurors, the presence of opposing experts can assist jurors' understanding of the expert evidence. Therefore, if experts are focused in on a specific methodological issue and are under a code of conduct to educate, it may be that challenging issues will be dealt with in a manner that provides for both the strength and weaknesses of both parties' positions. In addition when methodological issues are not serious enough to merit a 
finding of inadmissibility, judges may wish to issue special instructions to jurors regarding the weight to be assigned to evidence.

In summary, law's mission going forward will be to ensure that lessons learned regarding science's best practices go on to influence judicial decision making. Daubert presents a sensible framework whereby testing, error rate, and peer review can be drilled down into to more specific replicability-promoting concepts (e.g., direct replication, rigorous peer review, new statistics). How these concepts are worked into judicial practice largely depends on the complexity of the issue and the resources available to judges.

\section{Conclusion}

While much of the above discussion sounds pessimistic, the outlook within science is quite hopeful. Even before recent revelations, a great deal of science was performed and reported with care and rigor. And with tangible changes such as the work being done by the Open Science Framework and the editorial changes at leading academic outlets, there is reason to believe that bodies of work will only become more reliable. For instance, the Open Science Framework recently released its first report (Klein et al., 2013) on the replication attempts of several leading psychological theories. This effort found that many effects were reproducible by independent laboratories, with only a few (and indeed those that had already attracted some apprehension, i.e., some priming effects; see Yong, 2012a) resting on uncertain ground (e.g., Carter, Ferguson \& Hassin, 2011; Caruso, Vohs, Baxter, \& Waytz, 2013).

The large-scale self-correction science is undertaking is indeed heartening. But while science involves abstractions-theories that can withstand periods where the evidence self-corrects-law is not allowed the same liberties. Litigation requires immediate findings of fact, and as such the replicability crisis provides an important cautionary tale. It is possible that history will repeat itself, and the norms being developed in response to the replicability crisis never become widely adopted. In that case, to ensure the highest quality of science impacts legal proceedings, it will be up to the legal profession to ensure that lessons from the past are not forgotten. I am optimistic about the capability of judicial actors in adopting these best practices. Daubert may not have been designed with the replicability crisis in mind, but it provides a framework that judges - with proper training and guidance-can follow to account for most replicability-related issues.

\section{References}

Abelson, R. P. (1995). Statistics as a principled argument. Hillsdale, NJ: Lawrence Erlbaum Publishers.

American Psychological Association. (2009). Publication manual of the American Psychological Association (6th ed.). Washington, DC: Author.

Aronson, E. (1977). Research in social psychology as a leap of faith. Personality and Social Psychology Bulletin, 3, 190-195. doi:10.1177/ 014616727700300206

Bakker, M., van Dijk, A., \& Wicherts, J. M. (2012). The rules of the game called psychological science. Perspectives on Psychological Science, 7 , 543-554. doi:10.1177/1745691612459060

Beecher-Monas, E. (1998). Blinded by science: How judges avoid the science in scientific evidence. Temple Law Review, 71, 55-102.

Bem, D. J. (2011). Feeling the future: Experimental evidence for anomalous retroactive influences on cognition and affect. Journal of Personality and Social Psychology, 100, 407-425. doi:10.1037/a0021524
Berger, M. (1994). Novel forensic evidence: The need for court-appointed experts after Daubert. Shepard's Expert and Scientific Evidence, 1, 487.

Bernstein, D. E., \& Jackson, J. D. (2004). The Daubert trilogy in the states. Jurimetrics, 4, 351.

Black, B., Ayala, F. J., \& Saffran-Brinks, C. (1994). Science and the law in the wake of Daubert: A new search for scientific knowledge. Texas Law Review, 72, 715-802.

Bohannon, J. (2013). Who's afraid of peer review? Science, 342, 60-65. doi:10.1126/science. 342.6154 .60

Bower, B. (2012). The hot and the cold of priming. Science News, 181, 26-29. doi:10.1002/scin.5591811025

Brown, M., Tallon, J., \& Groscup, J. (2008, March). The effectiveness of opposing expert testimony as an expert reliability safeguard. In J. Groscup (Chair), Scientific reliability in the courtroom: Jurors' assessments of scientific evidence and legal safeguards. Symposium conducted at the annual meeting of the American Psychology-Law Society, Jacksonville, FL.

Brown v Entertainment Merchants Association, 131 S. Ct. 2729, 2768 (2011). (Breyer, J., dissenting).

Button, K. S., Ioannidis, J. P. A., Mokryz, C., Nosek, B. A., Flint, J., Robinson, E. S. J., \& Munafo, M. R. (2013). Power failure: Why small sample size undermines the reliability of neuroscience. Nature Reviews Neuroscience, 14, 365-376. doi:10.1038/nrn3475

Carey, B. (2011, November 3). Fraud case seen as red flag for psychology research. The New York Times, p. A3.

Carter, T. J., Ferguson, M. J., \& Hassin, R. R. (2011). A single exposure to the American flag shifts support toward Republicanism up to 8 months later. Psychological Science, 22, 1011-1018. doi:10.1177/ 0956797611414726

Caruso, E. M., Vohs, K. D., Baxter, B., \& Waytz, A. (2013). Mere exposure to money increases endorsement of free-market systems and social inequality. Journal of Experimental Psychology: General, 142, 301-306. doi:10.1037/a0029288

Carver, R. P. (1978). The case against statistical significance testing. Harvard Educational Review, 48, 378-399.

Cecil, J. S., \& Willging, T. E. (1993). Court-appointed experts: Defining the role of experts appointed under Federal Rule of Evidence 706 (pp. 83-88). Washington, DC: Federal Judicial Center.

Cheng, E. K., \& Yoon, A. H. (2005). Does Frye or Daubert matter? A study of scientific admissibility standards. Virginia Law Review, 91, 471-513.

Chesebro, K. J. (1994). Taking Daubert's "focus" seriously: The methodology/conclusion distinction, Cardozo Law Review, 15, 1745.

Chin, J. M., \& Schooler, J. W. (2008). Why do words hurt? Content, process, and criterion shift accounts of verbal overshadowing. European Journal of Cognitive Psychology, 20, 396-413. doi:10.1080/ 09541440701728623

Christophersen v Allied-Signal Corp., 939 f. 2d 1106 (5th Cir. 1991).

Cohen, J. (1994). The earth is round $(p<.05)$. American Psychologist, 49 , 997-1003. doi:10.1037/0003-066X.49.12.997

Cosmides, L., \& Tooby, J. (1996). Are humans good intuitive statisticians after all?: Rethinking some conclusions of the literature on judgment under uncertainty. Cognition, 58, 1-73. doi:10.1016/0010-0277(95)00664-8

Coursol, A., \& Wagner, E. (1986). Effect of positive findings on submission and acceptance rates: A note on meta-analysis bias. Professional Psychology: Research and Practice, 17, 136-137. doi:10.1037/07357028.17.2.136

Cumming, G. (2014). The new statistics: Why and how. Psychological Science, 25, 7-29. doi:10.1177/0956797613504966

Daubert v. Merrell Dow Pharmaceuticals, Inc. 509 U.S. 579-595. (1993).

Davis, K. C. (1942). An approach to problems of evidence in the administrative process. Harvard Law Review, 55, 364-425. doi:10.2307/ 1335092 
Dickersin, K. (1990). The existence of publication bias and risk factors for its occurrence. Journal of the American Medical Association, 263, 1385-1389. doi:10.1001/jama.1990.03440100097014

Dickersin, K. (1987). Publication bias and clinical trials. Controlled Clinical Trials, 8, 343-353. doi:10.1016/0197-2456(87)90155-3

Editorial. (2013). Announcement: Reducing our irreproducibility. Nature, 496, 398. doi:10.1038/496398a

Eich, E. (2014). Business not as usual. Psychological Science, 25, 3-6. doi:10.1177/0956797613512465

Faigman, D. L. (1999). Legal alchemy: The use and misuse of science in the law. New York, NY: W. H Freeman and Company.

Faigman, D. L., Blumenthal, J. A., Cheng, E. K., Mnookin, J. L., Murphy, E. E., \& Sanders, J. (2014). Modern scientific evidence: The law and science of expert testimony (Vols. 1-5). Eagen, MN: Thomson/West.

Faigman, D. L., \& Monahan, J. (2009). Standards of legal admissibility and their implications for psychological science. In J. L. Skeem, K. S. Douglas, \& S. O. Lilienfeld (Eds.), Psychological science in the courtroom: Consensus and controversy (pp. 3-25). New York, NY: Guilford Press.

Faigman, D. L., Monahan, J., \& Slobogin, C. (2014). Group to individual (G2i) inference in scientific expert testimony. University of Chicago Law Review, 81(2). Advance online publication. doi:10.2139/ssrn .2298909

Faigman, D. L., Saks, M. J., Sanders, J., \& Cheng, E. K. (2008). Modern scientific evidence: Forensics. Eagen, MN: West Academic Publishing.

Fanelli, D. (2012). Negative results are disappearing from most disciplines and countries. Scientometrics, 90, 891-904. doi:10.1007/s11192-0110494-7

Federal Rules of Evidence Rule 702 (2011a). Retrieved from http://www .law.cornell.edu/rules/fre/rule_702

Federal Rules of Evidence Rule 706 (2011b). Retrieved from http://www .law.cornell.edu/rules/fre/rule_706

Friedman, R. D. (2003). Minimizing the jury over-valuation concern. Michigan State Law Review, 967-986.

Frye v. United States. 293 F. 1013, 1014. (D. C. Cir. 1923).

Funder, D. C., Levine, J. M., Mackie, D. M., Morf, C. C., Vazire, S., \& West, S. G. (2014). Improving the dependability of research in personality and social psychology: Recommendations for research and educational practice. Personality and Social Psychology Review, 18, 3-12. doi:10.1177/1088868313507536

Galak, J. (2012). Correcting the past: Failure to replicate psi. Journal of Personality and Social Psychology, 103, 933-948. doi:10.1037/ a0029709

Gastwirth, J. T. (1992). Statistical reasoning in the legal setting. The American Statistician, 46, 55-56.

Gatowski, S. I. (2001). Asking the gatekeepers: A national survey of judges on judging expert evidence in a post-Daubert world. Law and Human Behavior, 25, 433-458. doi:10.1023/A:1012899030937

General Electric Co. v Joiner. 522 U.S. 136. (1997).

Giner-Sorolla, R. (2012). Science or art? How aesthetic standards grease the way through the publication bottleneck but undermine science. Perspectives on Psychological Science, 7, 562-571.

Goudge, S. T. (2008). Inquiry into pediatric forensic pathology in Ontario. Retrieved from http://www.attorneygeneral.jus.gov.on.ca/inquiries/goudge/ report/index.html

Greenwald, A. G. (1975). Consequences of prejudice against the null hypothesis. Psychological Bulletin, 82, 1-20. doi:10.1037/h0076157

Groscup, J. L., Penrod, S. D., Studebaker, C. A., Huss, M. T., \& O'Neil, K. M. (2002). The effects of Daubert on the admissibility of expert testimony in state and federal criminal cases. Psychology, Public Policy, and Law, 8, 339-372. doi:10.1037/1076-8971.8.4.339

Gross, S. (1991). Expert evidence. Wisconsin Law Review, 1991, 11131232 .
Ioannidis, J. P. A. (2005). Why most published research findings are false. PLoS Med, 2(8), e124. doi:10.1371/journal.pmed.0020124

Ioannidis, J. P. A. (2005a). Contradicted and initially stronger effects in highly cited clinical research. Journal of the American Medical Association, 294, 218-228. doi:10.1001/jama.294.2.218

Jasonoff, S. (1996). Science at the bar: Law, science, and technology in America. Cambridge, MA: Harvard University Press.

John, L. K., Loewenstein, G., \& Prelec, D. (2012). Measuring the prevalence of questionable research practices with incentives for truth telling. Psychological Science, 23, 524-532. doi:10.1177/0956797611430953

Johnson, G. (2014, January 20). New truths that only one can see. The New York Times, p. D1.

Kahneman, D., \& Tversky, A. (1973). On the psychology of prediction. Psychological Review, 80, 237-251. doi:10.1037/h0034747

Kirk, R. E. (2003). The importance of effect magnitude. In S. F. Davis (Ed.), Handbook of research methods in experimental psychology (pp. 83-105). Malden, MA: Blackwell. doi:10.1002/9780470756973.ch5

Klein, R. A., Ratliff, K. A., Vianello, M., Adams, R. B., Jr. Bahnik, S., Bernstein, M. J., . . . Nosek, B. A. (2013). Investigating variation in replicability: The "Many Labs" Replication Project. Retrieved from Open Science Framework, osf.io/wx7ck.

Kovera, M. B., \& McAuliff, B. D. (2000). The effects of peer review and evidence quality on judge evaluations of psychological science: Are judges effective gatekeepers? Journal of Applied Psychology, 85, 574586. doi:10.1037/0021-9010.85.4.574

Kovera, M. B., McAuliff, B. D., \& Hebert, K. S. (1999). Reasoning about scientific evidence: effects of juror gender and evidence quality on juror decisions in a hostile work environment case. Journal of Applied Psychology, 84, 362.

Kumho Tire Co. Ltd. v Carmichael. 526 U.S. 137. (1999).

Larsen, A. O. (2013). Factual precedents. University of Pennsylvania Law Review, 162, 59.

Lehrer, J. (2010, December 13). The truth wears off: Is there something wrong with the scientific method? The New Yorker. Retrieved from http://www.newyorker.com/reporting/2010/12/13/101213fa_fact_lehrer

Likwornik, H. (2011). Bayes rules-A Bayesian-intuit approach to legal evidence (Unpublished doctoral dissertation). University of Toronto, Toronto, Canada. Retrieved from https://tspace.library.utoronto.ca/ bitstream/1807/32076/1/Likwornik_Helena_M_201111_PhD_thesis.pdf

Lilienfeld, S. O. (2002). The scientific review of mental health practice: Our raison d'etre. The Scientific Review of Mental Health Practice, 1, 5-10. Retrieved from http://www.srmhp.org/0101/raison-detre.html

Lilienfeld, S. O., \& Landfield, K. (2008). Science and pseudoscience in law enforcement: A user-friendly primer. Criminal Justice and Behavior, 35, 1215-1230. doi: $10.1177 / 0093854808321526$

Lilienfeld, S. O., Lynn, S. J., \& Lohr, J. M. (2004). Science and pseudoscience in clinical psychology. New York, NY: Guilford Press.

Lykken, D. T., Macindoe, I., \& Tellegen, A. (1972). Preception: Autonomic response to shock as a function of predictability in time and locus. Psychophysiology, 9, 318-333.

Mahoney, M. J. (1977). Publication prejudices: An experimental study of confirmatory bias in the peer review system. Cognitive Therapy and Research, 1, 161-175. doi:10.1007/BF01173636

Makel, M. C., Plucker, J. A., \& Hegarty, B. (2012). Replications in psychological research: How often do they really occur? Perspectives on Psychological Science, 7, 537-542. doi:10.1177/1745691612460688

McAuliff, B. D., \& Groscup, J. L. (2009. Daubert and psychological science in court. In J. L. Skeem, K. S. Douglas, \& S. O. Lilienfeld (Eds.), Psychological science in the courtroom: Consensus and controversy (pp. 26-52). New York, NY: Guilford Press.

McAuliff, B. D. Kovera, M. B., \& Nunez, G. (2009). Can jurors recognize missing control groups, confounds, and experimenter bias in psychological science? Law and Human Behavior, 33, 247-257. doi:10.1007/ s10979-008-9133-0 
McNutt, M. (2014). Reproducibility. Science, 343, 229. doi:10.1126/ science. 1250475

Meissner, C. A., \& Brigham, J. C. (2001). A meta-analysis of the verbal overshadowing effect in face identification. Applied Cognitive Psychology, 15, 603-616. doi:10.1002/acp.728

Merlino, M. L., Dillehay, R., Dahir, V., \& Maxwell, D. (2003). Science education or judges: What where, and by whom? Judicature, 86, 210.

Monahan, J., \& Walker, L. (1991). Judicial use of social science research. Law and Human Behavior, 15, 571-584. doi:10.1007/BF01065853

Muller v Oregon, 208 US 412 (1908).

Neuroskeptic. (2011, July 15). Violent brains in the Supreme Court [Web $\log$ post]. Retrieved from http://neuroskeptic.blogspot.ca/2011/07/ violent-brains-in-supreme-court.html

Open Science Collaboration. (2012). An open, large-scale, collaborative effort to estimate the reproducibility of psychological science. Perspectives on Psychological Science, 7, 657-660. doi:10.1177/1745691612462588

Pashler, H., \& Harris, C. R. (2012). Is the replicability crisis overblown? Three arguments examined. Perspectives on Psychological Science, 7, 531-536. doi:10.1177/1745691612463401

Pashler, H., \& Wagenmakers, E. (2012). Editors' introduction to the special section on replicability in psychological science: A crisis of confidence? Perspectives on Psychological Science, 7, 528-530. doi: $10.1177 / 1745691612465253$

Ritchie, S. J., Wiseman, R., \& French, C. C. (2012). Failing the future: Three unsuccessful attempts to replicate Bem's 'Retroactive Facilitation of Recall' effect. PLOS ONE, 7(3), e33423. doi:10.1371/journal.pone .0033423

Robinson, E. (2011). Not feeling the future: A failed replication of retroactive facilitation of memory recall. Journal for the Society of Psychical Research, 75, 142-147.

Rosenthal, R. (1979). The file drawer problem and tolerance for null results. Psychological Bulletin, 86, 638-641. doi:10.1037/0033-2909.86 .3 .638

R v Harris and others, [2005] EWCA Crim 1980.

R v JLJ, [2000] 2 SCR 600.

R v Mohan, [1994] 2 SCR 9.

Sanders, J., Diamond, S. S., \& Vidmar, N. (2002). Legal perceptions of science and expert knowledge. Psychology, Public Policy, and Law, 8, 139-153. doi:10.1037/1076-8971.8.2.139

Schauer, F. (2010). Can bad science be good evidence? Neuroscience, lie detection, and beyond. Cornell Law Review, 95, 1191-1220.

Schmidt, F. L. (1992). What do data really mean? Research findings, meta-analysis, and cumulative knowledge in psychology. American Psychologist, 47, 1173-1181. doi:10.1037/0003-066X.47.10.1173

Schooler, J. W. (2011). Unpublished results hide the decline effect. Nature, 470, 437. Retrieved from http://www.nature.com/news/2011/ 110223/full/470437a.html

Schwartz, A. (1997). A "Dogma of Empiricism" revisited: Daubert v. Merrell Dow Phamaceuticals, Inc. and the need to resurrect the philosophical insight of Frye v the United States. Harvard Journal of Law \& Technology, 10, 149-237.
Simmons, J. P., Nelson, L. D., \& Simonsohn, U. (2011). False positive psychology: Undisclosed flexibility in data collection and analysis allows presenting anything as significant. Psychological Science, 22, 1359-1366. doi:10.1177/0956797611417632

Simonsohn, U. (2013). Just post it: The lesson from two cases of fabricated data detected by statistics alone. Psychological Science, 24, 1875-1888. doi: $10.1177 / 0956797613480366$

Stegenga, J. (2011). Is meta-analysis the platinum standard of evidence? Studies in History and Philosophy of Science part C: Studies in History and Philosophy of Biological and Biomedical Sciences, 42, 497-507. doi:10.1016/j.shpsc.2011.07.003

Sterling, T. D. (1959). Publication decisions and their possible effects on inferences drawn from tests of significance-Or vice versa. Journal of the American Statistical Association, 54, 30-34. doi:10.1080/01621459 .1959 .10501497

Sterling v Velsicol Chem. Corp. 855 F. 2d 1188 (6th Cir. 1988).

Stoller, S. E., \& Wolpe, P. R. (2007). Emerging neurotechnologies for lie detection and the Fifth Amendment. American Journal of Law and Medicine, 33, 359-375.

Stroebe, W., Postmes, T., \& Spears, R. (2012). Scientific misconduct and the myth of self-correction in science. Perspectives on Psychological Science, 7, 670-688. doi:10.1177/1745691612460687

Tukey, J. W. (1969). Analyzing data: Sanctification or detective work. American Psychologist, 24, 83-91. doi:10.1037/h0027108

United States v Hall. 974 F. Supp. at 1202.

Vul, E., Harris, C., Winkielman, P., \& Pashler, H. (2009). Puzzingly high correlations in fMRI studies of emotion, personality, and social cognition. Perspectives on Psychological Science, 4, 274-290. doi:10.1111/ j.1745-6924.2009.01125.x

Wagenmakers, E. J., Wetzels, R., Boorsboom, D., \& van der Maas, H. L. J. (2011). Why psychologists must change the way they analyze their data: The case of Psi: Comment on Bem. Journal of Personality and Social Psychology, 100, 426-432. doi:10.1037/a0022790

Wicherts, J. M., \& Bakker, M. (2012). Publish (your data) or (let the data) perish! Why not publish your data too?. Intelligence, 40, 73-76.

Wicherts, J. M., Bakker, M., \& Molenaar, D. (2011). Willingness to share research data is related to the strength of the evidence and the quality of reporting statistical results. PLoS ONE, 6(11), e26828. doi:10.1371/ journal.pone. 0026828

Wilkinson, L. (1999). Statistical methods in psychology journals: Guidelines and explanations. American Psychologist, 54, 594-604. doi: 10.1037/0003-066X.54.8.594

Yong, E. (2012a, March 10). A failed replication attempt draws a scathing personal attack from a psychology professor. Discover Magazine [Web log post]. Retrieved from http://blogs.discovermagazine.Com/notrocketscience/ 2012/03/10/failed-replication-bargh-psychology-study-doyen

Yong, E. (2012b). Replication studies: Bad copy. Nature, 485, 298-300. doi: $10.1038 / 485298$ a

Received December 23, 2013

Revision received March 11, 2014

Accepted March 12, 2014 